\title{
Contribution of fish to intakes of micronutrients important for fetal development: a dietary survey of pregnant women in the Republic of Seychelles
}

\author{
Maxine P Bonham ${ }^{1, *}$, Emeir M Duffy ${ }^{1}$, Paula J Robson ${ }^{1}$, Julie M Wallace ${ }^{1}$, \\ Gary J Myers ${ }^{2}$, Philip W Davidson ${ }^{3}$, Tom W Clarkson ${ }^{4}$, Conrad F Shamlaye ${ }^{5}$, \\ JJ Strain ${ }^{1}$ and $M$ Barbara E Livingstone ${ }^{1}$ \\ ${ }^{1}$ Northern Ireland Centre for Food and Health (NICHE), Department of Biomedical Sciences, University of Ulster, \\ Coleraine BT52 1SA, UK: ${ }^{2}$ Division of Child Neurology, University of Rochester School of Medicine and \\ Dentistry, Rochester, NY, USA: ${ }^{3}$ Strong Centre for Developmental Disabilities, University of Rochester School of \\ Medicine and Dentistry, Rochester, NY, USA: ${ }^{4}$ Department of Environmental Medicine, University of Rochester, \\ Rochester, NY, USA: ${ }^{5}$ Ministry of Health, Victoria, Mahé, Republic of Seychelles
}

Submitted 20 February 2008: Accepted 16 September 2008: First published online 6 November 2008

\begin{abstract}
Objectives: To characterise the diets of pregnant women in the Republic of Seychelles and to determine the contribution of fish to intakes of nutrients important for fetal and neonatal development.

Design: Observational, prospective study.

Setting: Seychelles Child Development Centre, Mahé, Republic of Seychelles.

Subjects and methods: Pregnant women ( $n$ 300) were recruited at their first visit to an antenatal clinic. At 28 weeks' gestation subjects completed a $4 \mathrm{~d}$ diet diary ( $n$ 273) and intakes were analysed using dietary analysis software.

Results: Mean (SD) energy intake was $9 \cdot 0(2 \cdot 5) \mathrm{MJ} / \mathrm{d}$ and fat intakes were higher than UK recommendations for almost two-thirds of the cohort. Fish consumption was lower than in previous surveys, suggesting a move towards a more Westernised diet. Low intakes of a number of nutrients important during pregnancy for fetal development (Fe, Zn, Se and iodine) were observed. However, women who met the current recommendations for these nutrients consumed significantly more fish than those who did not $(97 v .73 \mathrm{~g} / \mathrm{d})$.

Conclusions: The present study highlights the importance of fish in the diet of pregnant Seychellois women for ensuring adequate intakes of micronutrients important in fetal development. Dietary patterns in Seychelles, however, are in a state of transition, with a move towards a Western-style diet as evidenced by higher fat and lower fish intakes. If these dietary trends continue and fish consumption declines further, micronutrient status may be compromised. These findings suggest caution in establishing public health policies that promote limitation of fish intake during pregnancy.
\end{abstract}

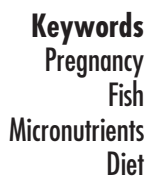

The nutritional status of women during pregnancy influences physiological outcomes in the child, including birth size ${ }^{(1,2)}$, later risk of CVD and diabetes ${ }^{(3,4)}$ and cognitive function ${ }^{(5)}$. Despite some concerns about exposure to methylmercury ${ }^{(6)}$, fish consumption during pregnancy provides an excellent source of dietary protein ${ }^{(7)}$ as well as a number of micronutrients essential for fetal development ${ }^{(8,9)}$ such as Fe, iodine, Zn, Se, choline and long-chain PUFA.

Iodine and Fe deficiencies are two of the most common nutritional deficiencies in the world. An estimated 30\% of the world's population inhabits areas of iodine deficiency $^{(10)}$ while Fe deficiency anaemia affects up to $50 \%$ of pregnant women in developing ${ }^{(11)}$ countries and up to
$25 \%$ of children under the age of 3 years, with higher rates observed in developing countries ${ }^{(10)}$. Correction of iodine deficiency in pregnancy can be achieved with supplementation and is associated with improved psychomotor test scores in infants ${ }^{(12)}$. Fe supplementation in children can improve mental and motor scores in standardised developmental assessments ${ }^{(13)}$. Maternal $\mathrm{Zn}$ status has been linked with infants' early behaviour ${ }^{(14)}$, with $\mathrm{Zn}$ supplementation during pregnancy associated with increased motor activity in the offspring ${ }^{(15)}$. Se is also a vital component of the maternal diet with essential roles in fetal development ${ }^{(16)}$. Se might influence fetal development directly by interacting with iodine in regulating 
thyroid function ${ }^{(17)}$ and might also have a protective role in the prevention of methylmercury toxicity ${ }^{(18)}$.

Long-chain PUFA play an important structural role in neural tissue, especially the brain and retina ${ }^{(19)}$. Fetal accretion is at its greatest in the third trimester of pregnancy $^{(20)}$ and supplementation with long-chain PUFA in pregnancy has been shown to improve cognitive function $^{(21)}$. Choline, a nutrient that can be synthesised de novo in the body, appears to be a conditionally essential dietary nutrient for optimal brain development both pre- and postnatally ${ }^{(22)}$. Supplementation with choline in animal models has indicated a life-long enhancement in spatial memory $^{(23)}$ and cognitive function ${ }^{(24)}$.

The Republic of Seychelles is a small tropical archipelagic state in the Indian Ocean with one of the highest per capita rates of fish consumption in the world ${ }^{(25)}$. The population consumes a traditional diet based around high fish consumption in conjunction with a high intake of fruit and vegetables. Such a diet would be expected to provide optimal nutrient intake with respect to those micronutrients of importance in infant development. Evidence has indicated that fish consumption has decreased by up to one-third over the last two decades as the Seychellois population adopts a more Western-style diet and lifestyle ${ }^{(26)}$. This has led to increased concern that if these trends continue, micronutrient status may be compromised. However, no study to date has examined in detail dietary patterns during pregnancy in this population. The aims of the current project, therefore, were to characterise the diets of pregnant Seychellois women and to determine the role that fish play in promoting adequate intakes of nutrients important for fetal and neonatal development.

\section{Materials and methods}

\section{Subjects}

A total of 300 pregnant women were recruited in 2001 from all ( $n 9)$ antenatal clinics on Mahé in the Republic of Seychelles. All eligible women attending the antenatal clinics for their first antenatal visit within a 3-month period, who met the inclusion criteria, were invited to participate on the study. Inclusion criteria were aged over 16 years, resident on Mahé (main island of the Seychelles archipelago and where $90 \%$ of the total population lives) and native-born Seychellois. The cohort of 300 represents one-fifth of total annual deliveries in Seychelles and 75\% of all women booking at antenatal clinics during the enrolment period, and was therefore considered to be a representative sample of the population. Women were excluded if they were vegetarian, or if they reported a serious medical illness such as insulin-dependent diabetes, toxaemia with seizures or a haematological disorder such as thalassaemia or sickle cell anaemia. The study was reviewed and approved by the Research Subjects Review Board in Seychelles and the appropriate
Research Subjects Review Boards of the collaborating partners.

\section{Dietary assessment}

Detailed information on the issues involved in establishing the dietary survey methodology in Seychelles is documented elsewhere ${ }^{(27)}$. Briefly, at 28 weeks' gestation detailed dietary information was collected from each subject by means of a prospective $4 \mathrm{~d}$ semi-quantitative food diary (two consecutive weekdays and two weekend days). The diet diaries were available in both English and Kreol language, and detailed instructions on completion of the diet diary were given to each subject by trained investigators.

Nurses, trained by nutritionists from the University of Ulster, reviewed the diaries within one week of completion, and errors and omissions were clarified with subjects. Data in the diet diaries were then converted to gram weights for input into a dietary analysis package (WISP version $2 \cdot 0$; Tinuviel Software, Warrington, UK). Package weights of imported food, much of which was from the UK at that time, were obtained from UK standard food portion sizes ${ }^{(28)}$.

The dietary analysis package, WISP, was supplemented with food composition and recipe data for additional foods consumed in Seychelles. These data were obtained from a variety of food composition tables from around the world including The Composition of South African Foods ${ }^{(29)}$ and The Concise New Zealand Food Composition Tables ${ }^{(30)}$. In addition, the energy and nutrient composition of ten of the most commonly consumed fish were chemically analysed (CCFRA Technology Ltd, Chipping Campden, UK) and nutrient values entered into the database. The WISP program was further augmented with data for the choline content of foods obtained from the US Department of Agriculture food composition database $^{(31)}$. Data were mapped to the most appropriate food codes in the UK database by a registered nutritionist. This process involved both matching for food name and nutrient profile.

\section{Antbropometry}

Maternal height and weight were measured according to standardised procedures by trained nurses at enrolment into the study and BMI was calculated as [weight (kg)]/ [height $(\mathrm{m})]^{2}$. Measuring equipment in each of the participating antenatal clinics was calibrated prior to initiation of the study, and regularly throughout the project, by the Seychelles Bureau of Standards.

\section{Estimated BMR}

$\operatorname{BMR}(\mathrm{MJ} / \mathrm{d})$ was estimated for all subjects at enrolment into the study using the Schofield equations ${ }^{(32)}$. Depending on the age of the subject at enrolment the following equations were used:

$$
\begin{gathered}
\text { BMR }=0.057 \times \text { weight }+1 \cdot 184 \times \text { height }+0.411 \\
\text { for subjects aged } 18-30 \text { years }
\end{gathered}
$$


and

$$
\mathrm{BMR}=0.034 \times \text { weight }+0.006 \times \text { height }+3.530
$$

for subjects aged $>30$ years,

where weight is in kilograms and height is in metres.

\section{Under-reporting}

The level of under-reporting (MJ/d) of energy intake (EI) was determined as follows. Cut-off limits for EI:BMR were calculated as described by Goldberg et al. $^{(33)}$ using the following equation ${ }^{(34)}$ :

$$
\mathrm{EI}_{\text {rep }}: \mathrm{BMR}>\mathrm{PAL} \times \exp \left[\mathrm{SD}_{\min (\text { or max })} \times \frac{S / 100}{\sqrt{n}}\right],
$$

where PAL (physical activity level) was assumed to be $1.4 \times$ BMR as recommended by Prentice et $a l^{(35)}$ for the third trimester pregnancy; $S$ is a factor that accounts for variation in BMR, EI and PAL; $n$ is the number of subjects; and $\mathrm{SD}_{\min (\text { or max }}$ is -2 or $+2 \mathrm{SD}$ for the $95 \%$ upper confidence limit.

\section{Socio-economic status}

Socio-economic status (SES) was assigned to each participant using the Hollingshead four-factor score based on education, occupation, sex and marital status. Occupational scores were based on a list of Seychellois employment codes, as previously reported ${ }^{(36)}$.

\section{Statistical analysis}

All data were analysed using the SPSS $12 \cdot 0$ for Windows statistical software package (SPSS Inc., Chicago, IL, USA). Data for all variables were tested for normality and adjusted where necessary. To reduce the inaccuracies associated with estimating the extent of nutritional inadequacy in this population based on short-term dietary data collection, statistical methods were used to estimate the usual distribution of intakes based on the observed intakes. Adjustment of observed intakes was carried out as follows. Dietary data were normalised, and within- and between-person variances were calculated. The mean intake of each subject was then adjusted as follows:

[(subject's mean intake - group mean intake)

$$
\left.\times\left(\mathrm{SD}_{\text {between }} / \mathrm{SD}_{\text {observed }}\right)\right]+ \text { group mean intake. }
$$

The resulting adjusted distributions were then used to compare reported nutrient intakes with dietary recommendations, using the cut-point $\operatorname{method}^{(37,38)}$. In the Republic of Seychelles, nutritional guidelines are based on the UK Dietary Reference Values (DRV) ${ }^{(39)}$.

To assess the potential impact of dietary misreporting on the extent of potential nutrient inadequacy, dietary intakes reported by the whole group were compared with those reported by subjects not classified as under-reporters using one-way ANOVA. Independent $t$ tests were used to examine for differences between fish consumption in subjects meeting nutrient requirements compared with those who did not. A significance level of $P<0 \cdot 05$ was used to evaluate all statistical outcomes.

\section{Results}

\section{Subject characteristics}

Of the 300 women recruited to the study at their first visit to an antenatal clinic (mean gestational age 12.5 weeks) dietary data were available for 273 women. Dropouts were for a combination of reasons including miscarriage/ abortion ( $n 12)$, not pregnant $(n 4)$, illness $(n 1)$, relocation ( $n 2)$ and non-compliance $(n 8)$. On average, women who participated in the study had a mean (SD) age of $27 \cdot 0$ $(6 \cdot 1)$ years, were $1 \cdot 60(6 \cdot 7) \mathrm{m}$ tall, weighed $66 \cdot 7(16 \cdot 6) \mathrm{kg}$ and had a BMI of $25 \cdot 9(6 \cdot 3) \mathrm{kg} / \mathrm{m}^{2}$ at enrolment. SES was assessed by the Hollingshead score ( $n$ 260). This score is divided into four groups: unskilled (13.5\%), semi-skilled $(25 \cdot 8 \%)$, skilled $(25 \cdot 4 \%)$ and business/professional $(35 \cdot 4 \%)$. The highest percentage of pregnant women were in the business/professional category. SES had no influence on nutrient densities (nutrient intake/MJ energy intake; data not shown).

Estimated BMR was calculated at enrolment to the study. For the group as a whole, mean (SD) BMR was 5.98 $(0 \cdot 83) \mathrm{MJ} / \mathrm{d}$. Mean $\mathrm{EI}_{\mathrm{rep}}$ :BMR was 1.33. Calculation of cut-off values was based on a PAL of $1 \cdot 4 \times \mathrm{BMR}^{(35)}$. The daily variance in energy intake was $22.07 \%$ and the estimated BMR and physical activity levels were $8.5 \%$ and $15 \%$ respectively ${ }^{(34)}$, giving a cut-off for under-reporting of $1.37 \times$ BMR. A total of 109 women $(39.6 \%)$ were classified as under-reporters.

\section{Energy and macronutrient intakes}

Table 1 presents mean (SD) and median (5th, 95th percentiles) dietary intakes of pregnant women in Seychelles for the group as a whole and after excluding underreporters. For the whole group, median (5th, 95th percentiles) daily energy intake was $8.9(5 \cdot 0,13 \cdot 4) \mathrm{MJ}$ and comprised $48 \cdot 6(37 \cdot 8,56 \cdot 8) \%$ carbohydrate, $36 \cdot 3(28 \cdot 8$, $44 \cdot 0) \%$ fat and $15 \cdot 4(12 \cdot 0,19 \cdot 4) \%$ protein. Comparisons between nutrient intakes of the whole group ( $n$ 273) and those who were classified as non under-reporters ( $n$ 164) indicated a significantly higher intake of all nutrients except vitamin A in those subjects who were not deemed to be under-reporters. Macronutrient intake expressed in relative terms (percentage of energy) was not significantly different between the group as a whole and after excluding under-reporting, suggesting that under-reporting was not macronutrient-specific.

\section{Nutritional adequacy}

The Estimated Average Requirement (EAR) ${ }^{(39)}$ is advocated by the Institute of Medicine ${ }^{(40)}$ as the most appropriate yardstick for assessing nutritional adequacy. Preferably, these comparisons should be made on data that have been statistically adjusted to estimate the distribution of usual intakes from the observed intakes ${ }^{(37)}$. Table 2 presents a comparison of adjusted mean dietary intakes with the UK EAR for the group as a whole and after excluding under-reporters. Where nutrient 
Table 1 Observed nutrient intakes in pregnant Seychellois women including ( $n$ 273) and excluding under-reporters $(n$ 164)

\begin{tabular}{|c|c|c|c|c|c|c|c|c|c|}
\hline & \multicolumn{4}{|c|}{ Estimated dietary intake ( $n$ 273) } & \multicolumn{4}{|c|}{$\begin{array}{l}\text { Estimated dietary intake (subjects above } \\
\text { cut-off for under-reporting*; } n \text { 164) }\end{array}$} & \multirow[b]{2}{*}{$P$ value } \\
\hline & Mean & SD & Median & P5, P95 & Mean & SD & Median & P5, P95 & \\
\hline Energy $(\mathrm{MJ} / \mathrm{d})$ & $9 \cdot 0$ & $2 \cdot 5$ & $8 \cdot 9$ & $5 \cdot 0,13 \cdot 4$ & $10 \cdot 4$ & $2 \cdot 0$ & $10 \cdot 2$ & $7 \cdot 8,14 \cdot 6$ & 0.000 \\
\hline Energy (kcal/d) & 2149 & $59 \overline{7}$ & 2120 & 1206,3197 & 2474 & 486 & 2417 & 1858,3470 & 0.000 \\
\hline Fat $(\mathrm{g} / \mathrm{d})$ & $87 \cdot 2$ & $27 \cdot 7$ & $84 \cdot 1$ & $47 \cdot 6,137 \cdot 2$ & $101 \cdot 1$ & $24 \cdot 8$ & $96 \cdot 7$ & $68 \cdot 0,146 \cdot 8$ & 0.000 \\
\hline Fat $(\%)$ & $36 \cdot \overline{5}$ & $4 \cdot 8$ & $36 \cdot 3$ & $28 \cdot 8,44 \cdot 0$ & $36 \cdot 6$ & $4 \cdot 8$ & $36 \cdot 3$ & $29 \cdot 1,45 \cdot 1$ & 0.607 \\
\hline Saturated fat $(g / d)$ & $34 \cdot 8$ & $12 \cdot 3$ & $33 \cdot 5$ & $16 \cdot 3,57 \cdot 5$ & $40 \cdot 3$ & $11 \cdot 6$ & $37 \cdot 7$ & $24 \cdot 2,63 \cdot 4$ & 0.000 \\
\hline Saturated fat (\%) & $14 \cdot 5$ & $2 \cdot 8$ & $14 \cdot 5$ & $10 \cdot 2,19 \cdot 2$ & $14 \cdot 6$ & $2 \cdot 8$ & $14 \cdot 6$ & $10 \cdot 2,19 \cdot 4$ & 0.709 \\
\hline $\mathrm{CHO}(\mathrm{g} / \mathrm{d})$ & 277 & 83 & 268 & 153,405 & 319 & 71 & 310 & 230,475 & 0.000 \\
\hline $\mathrm{CHO}(\%)$ & $48 \cdot 1$ & $5 \cdot 7$ & $48 \cdot 6$ & $37 \cdot 8,56 \cdot 8$ & $48 \cdot 1$ & $5 \cdot 4$ & $48 \cdot 6$ & $37 \cdot 8,56 \cdot 3$ & 0.987 \\
\hline $\operatorname{NMES}(\mathrm{g} / \mathrm{d})$ & $54 \cdot 9$ & $29 \cdot 2$ & $52 \cdot 0$ & $15 \cdot 7,107 \cdot 4$ & $64 \cdot 30$ & $30 \cdot 2$ & $60 \cdot 7$ & $23 \cdot 7,120 \cdot 5$ & 0.001 \\
\hline NMES (\%) & $9 \cdot 6$ & $4 \cdot 7$ & $9 \cdot 0$ & $3 \cdot 5,18 \cdot 1$ & $9 \cdot 8$ & $4 \cdot 1$ & $9 \cdot 1$ & $3 \cdot 6,18 \cdot 1$ & 0.744 \\
\hline Protein (g/d) & $82 \cdot 2$ & $24 \cdot 0$ & $81 \cdot 3$ & $46 \cdot 0,128 \cdot 4$ & $93 \cdot 6$ & $21 \cdot 0$ & $92 \cdot 7$ & $62 \cdot 0,132 \cdot 1$ & 0.000 \\
\hline Protein (\%) & $15 \cdot 4$ & $2 \cdot 2$ & $15 \cdot 4$ & $12 \cdot 0,19 \cdot 4$ & $15 \cdot 2$ & $2 \cdot 0$ & $15 \cdot 1$ & $12 \cdot 0,19 \cdot 1$ & 0.288 \\
\hline Fibre $(\mathrm{g} / \mathrm{d})$ & $10 \cdot 5$ & $4 \cdot 0$ & $10 \cdot 8$ & $4 \cdot 1,20 \cdot 0$ & $12 \cdot 2$ & $3 \cdot 6$ & $11 \cdot 7$ & $7 \cdot 0,17 \cdot 9$ & 0.000 \\
\hline $\operatorname{Vitamin} A(\mu \mathrm{g} / \mathrm{d})$ & 588 & 713 & 376 & 150,2011 & 675 & 776 & 437 & 200,2354 & 0.241 \\
\hline Vitamin $C(\mathrm{mg} / \mathrm{d})$ & 144 & 77 & 133 & 45,265 & 169 & 78 & 161 & 58,290 & 0.001 \\
\hline Vitamin $B_{1}(\mathrm{mg} / \mathrm{d})$ & $1 \cdot 3$ & 0.4 & $1 \cdot 2$ & $0 \cdot 6,2 \cdot 0$ & $1 \cdot 4$ & 0.4 & $1 \cdot 3$ & $0 \cdot 9,2 \cdot 1$ & 0.000 \\
\hline Vitamin $B_{2}(\mathrm{mg} / \mathrm{d})$ & $1 \cdot 6$ & 0.7 & $1 \cdot 52$ & $0 \cdot 7,2 \cdot 8$ & 1.9 & 0.7 & $1 \cdot 8$ & $1 \cdot 0,2 \cdot 9$ & 0.000 \\
\hline Niacin $(\mathrm{mg} / \mathrm{d})$ & $16 \cdot 5$ & $5 \cdot 8$ & $16 \cdot 2$ & $8 \cdot 1,26 \cdot 8$ & $18 \cdot 6$ & $5 \cdot 4$ & $18 \cdot 0$ & $11 \cdot 4,28 \cdot 7$ & 0.000 \\
\hline Vitamin $B_{6}(\mathrm{mg} / \mathrm{d})$ & $1 \cdot 8$ & 0.6 & $1 \cdot \overline{8}$ & $0.9,2.8$ & $2 \cdot 1$ & 0.5 & $2 \cdot 0$ & $1 \cdot 5,2 \cdot 9$ & 0.000 \\
\hline Vitamin $B_{12}(\mu \mathrm{g} / \mathrm{d})$ & $5 \cdot 5$ & $3 \cdot 0$ & $4 \cdot 7$ & $2 \cdot 4,11 \cdot 2$ & $6 \cdot 3$ & $3 \cdot 1$ & $5 \cdot 5$ & $2 \cdot 9,12 \cdot 1$ & 0.009 \\
\hline Folate $(\mu \mathrm{g} / \mathrm{d})$ & 230 & 91 & 218 & 42,113 & 259 & 86 & 237 & 156,475 & 0.001 \\
\hline Choline $(\mathrm{mg} / \mathrm{d})$ & 208 & 81 & 204 & 93,370 & 229 & 79 & 221 & 111,387 & 0.009 \\
\hline $\mathrm{Ca}(\mathrm{mg} / \mathrm{d})$ & 948 & 389 & 916 & 388,1671 & 1104 & 376 & 1061 & 548,1764 & 0.000 \\
\hline $\mathrm{Mg}(\mathrm{mg} / \mathrm{d})$ & 234 & 74 & 232 & 119,360 & 272 & 63 & 264 & 183,386 & 0.000 \\
\hline $\mathrm{Fe}(\mathrm{mg} / \mathrm{d})$ & $9 \cdot 5$ & $3 \cdot 1$ & $9 \cdot 1$ & $5 \cdot 0,15 \cdot 5$ & $10 \cdot 9$ & $2 \cdot 7$ & $10 \cdot 6$ & $7 \cdot 2,15 \cdot 9$ & 0.000 \\
\hline $\mathrm{Cu}(\mathrm{mg} / \mathrm{d})$ & $1 \cdot 2$ & 0.4 & $1 \cdot 2$ & $0.6,1.9$ & $1 \cdot 4$ & 0.4 & $1 \cdot 3$ & $0 \cdot 9,2 \cdot 1$ & 0.000 \\
\hline $\mathrm{Zn}(\mathrm{mg} / \mathrm{d})$ & $8 \cdot 6$ & $2 \cdot 6$ & $8 \cdot 4$ & $4 \cdot 6,13 \cdot 1$ & $9 \cdot 9$ & $2 \cdot 2$ & $9 \cdot 7$ & $6 \cdot 4,13 \cdot 9$ & 0.000 \\
\hline lodine $(\mu \mathrm{g} / \mathrm{d})$ & 134 & 57 & 123 & 56,237 & 151 & 53 & 141 & 76,249 & 0.002 \\
\hline $\operatorname{Se}(\mu g / d)$ & $79 \cdot 3$ & $26 \cdot 4$ & $77 \cdot 4$ & $39 \cdot 9,129 \cdot 4$ & $89 \cdot 3$ & $25 \cdot 0$ & $85 \cdot 6$ & $48 \cdot 3,135 \cdot 7$ & 0.000 \\
\hline
\end{tabular}

P5, 5th percentile; P95, 95th percentile; CHO, carbohydrate; NMES, non-milk extrinsic sugars.

${ }^{*}$ Cut-off points for under-reporting were calculated as described by Goldberg et al. ${ }^{(33)}$.

$+P<0.05$ indicates a significant difference in dietary intakes between all subjects $(n 273)$ and those who did not under-report ( $n$ 164).

recommendations for pregnancy are available (applicable to Reference Nutrient Intakes (RNI) only), comparisons have been made using the adjusted dietary intakes with the appropriate RNI (specifically protein, vitamins $\mathrm{A}, \mathrm{B}_{1}$, $\mathrm{B}_{2}$, folate and vitamin $\mathrm{C}$ ) and also for nutrients where only $\mathrm{RNI}$ are stated $(\mathrm{Cu}$, iodine and $\mathrm{Se})$. As there are recommendations for a number of nutrients during pregnancy, comparison with RNI was more frequent than with EAR.

When fat and carbohydrate intakes (expressed as a percentage of energy) were compared with UK DRV, saturated fat intakes for $>90 \%$ of the study group were in excess of recommendations. Non-milk extrinsic sugar intakes, however, were below the recommended DRV of $\leq 10 \%$ energy intake for $97 \%$ of the population.

Vitamins $\mathrm{B}_{6}$ and $\mathrm{B}_{12}$ were the only nutrients that met recommended requirements (RNI) in the population as a whole. Intakes of protein and vitamin $\mathrm{C}$ when compared with the RNI were deemed to be adequate for $>90 \%$ of the population. When under-reporters were excluded, the percentage of the group attaining the appropriate DRV was higher for all nutrients except vitamin A (comparison with RNI). Intakes of nutrients specifically important in pregnancy such as Fe and $\mathrm{Zn}$ (comparison with EAR), folate and Se (comparison with RNI) were evaluated and low levels were observed in 80.6\%, 8.4\%, $91 \cdot 2 \%$ and $20 \cdot 2 \%$ of the population as a whole, respectively. The exclusion of under-reporters reduced these values to $69 \cdot 5 \%, 0 \%, 84 \cdot 8 \%$ and $9 \cdot 1 \%$, respectively.

\section{Contribution of food groups to nutrient intakes}

Average fish intake was $76 \mathrm{~g} / \mathrm{d}$ and consumed by $98 \%$ of all subjects. The most commonly consumed fish were karang (32\%), mackerel (12\%), spinefoot shoemaker $(12 \%)$, fresh tuna (6\%), tinned tuna (6\%) and barracuda (5\%). Meat and fish made similar contributions to protein intake and together accounted for $40 \%$ of overall protein intake. Vegetables (excluding potatoes) were consumed by all subjects and fruit/fruit juice was consumed by $95 \cdot 2 \%$ of the subjects (data not shown).

Table 3 presents the contribution of the various food groups to the dietary intake of the nutrients of specific interest in pregnancy, i.e. Fe, Zn, Se, iodine and choline. The main food groups contributing to Fe intakes were vegetables, meat and bread and rolls. Egg consumption provided over one-third of choline intakes, with the second largest contribution coming from the fish and fish products food group. Although not the most nutrient-dense 


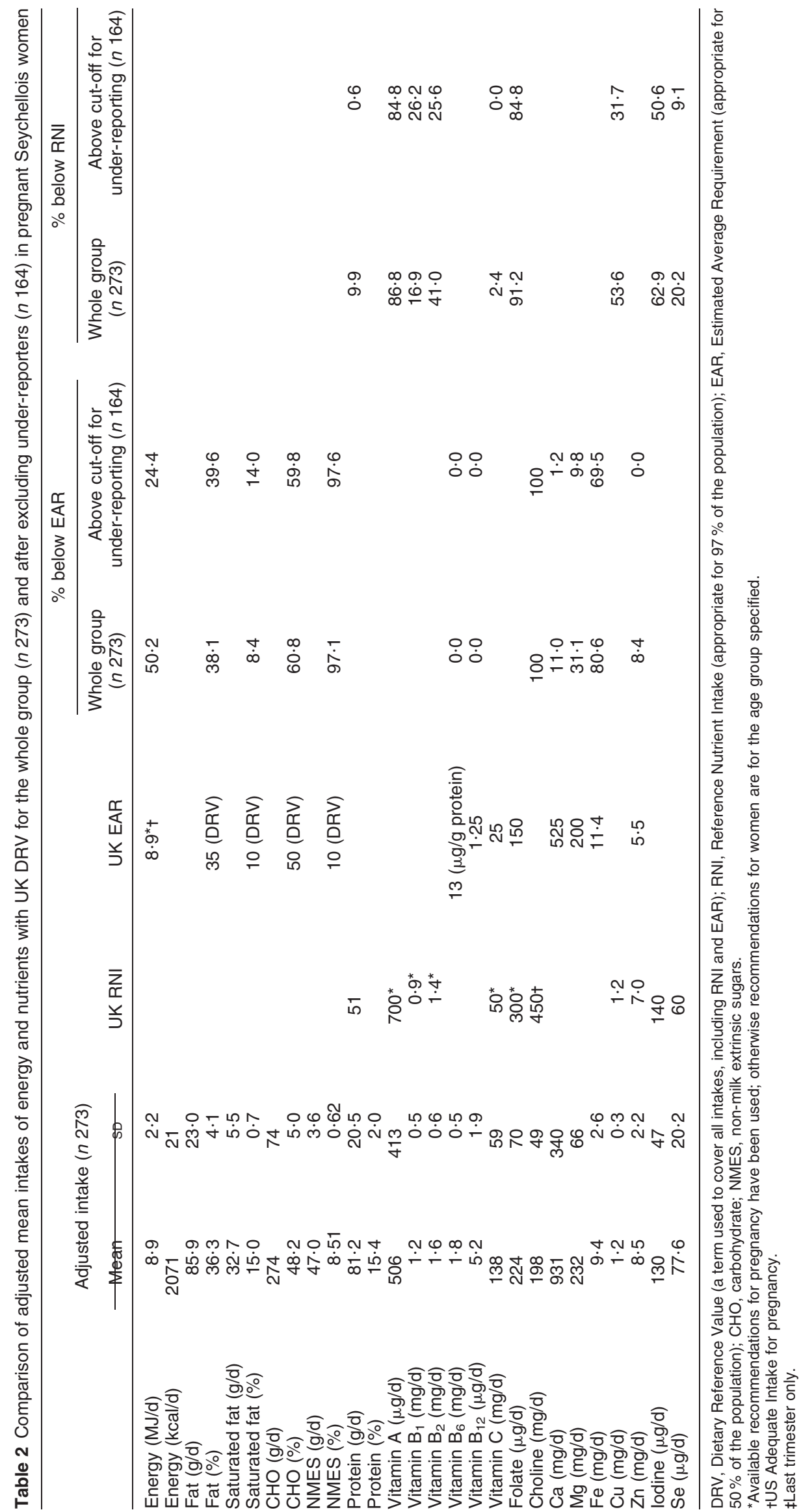


food in terms of Se content, bread and rolls were consumed in amounts that made this food group the most important source of dietary Se, followed by fish. Red meat was the best source of dietary $\mathrm{Zn}$. In terms of overall dietary contribution of the aforementioned nutrients which have an important role in pregnancy, fish was the second most widespread source of iodine, Se and choline, and contributed to both $\mathrm{Zn}$ and Fe intakes.

Separation of the subjects into those who met the appropriate recommendations for $\mathrm{Fe}, \mathrm{Zn}$, iodine and $\mathrm{Se}$ ( $n$ 35) and those who met recommendations for three or fewer of these nutrients indicated a significantly greater mean (SD) fish consumption of $98.6(65 \cdot 8) \mathrm{g} / \mathrm{d}$ compared with $73 \cdot 2(42 \cdot 1) \mathrm{g} / \mathrm{d}(P<0 \cdot 05)$.

\section{Discussion}

The present paper reports dietary habits of pregnant women in the Republic of Seychelles, a small island developing state and the location for a number of longterm observational epidemiological studies examining the effect of fish consumption on infant neurodevelopment ${ }^{(36,41)}$. Mean (SD) weekly fish consumption was high at approximately 527 (327) $\mathrm{g}^{(42)}$ and therefore would be expected to contribute considerably to dietary intakes of micronutrients such as iodine, Se and Zn. Indeed, women meeting dietary recommendations for all of the aforementioned micronutrients had a significantly higher fish intake. In the group as a whole, however, comparison of micronutrient intakes (adjusted means) with UK EAR or RNI where appropriate indicated noticeable shortfalls. Dietary Fe requirements, for example, were not met by $80 \cdot 6 \%$ of the population (based on UK EAR). The Institute of Medicine have concluded that $\mathrm{Fe}$ is the only nutrient in pregnancy for which diet alone cannot meet requirements $^{(43)}$. Supplements are routinely supplied during pregnancy in Seychelles but uptake appears sporadic at best ${ }^{(44)}$. Although some dietary intakes observed in our study were low, the findings are comparable to those in populations in the UK, Mexico and South Africa ${ }^{(45-47)}$.

Initial analysis of the current cohort suggested that iodine intakes did not meet recommendations in $62.9 \%$ of the study group (based on UK RNI). Low intakes of dietary iodine have also been observed in women of childbearing age in Europe and are approximately $50 \%$ of recommendations ${ }^{(48)}$. This apparent shortfall in iodine intake is of concern as low iodine status in pregnancy has adverse implications for fetal neurodevelopment ${ }^{(49)}$. However, intakes are likely to have been underestimated as the iodine content of some fish species consumed in Seychelles is unknown and therefore was unaccounted for in the dietary analysis. Subsequent analysis, using an assumed average iodine concentration per $100 \mathrm{~g}$ fish, suggested that $36 \cdot 3 \%$ did not meet requirements. Dietary 
intakes of Se were adequate in $79 \cdot 8 \%$ of the whole group (based on UK RNI). Although not the richest source of Se, bread had high habitual consumption that ensured this food group was the highest contributor to dietary Se, followed by fish. Adequate Se status might be important in high fish-eating populations given its possible role in counteracting the toxicity of methylmercury, which is also present in fish. Although $\mathrm{Zn}$ deficiency has been estimated to be as high as $25 \%$ in the world's population ${ }^{(50)}$, in our study group inadequate $\mathrm{Zn}$ intakes (based on UK EAR) were seen in only $8 \cdot 4 \%$ of the population. However, after excluding under-reporters, the levels of apparent nutritional inadequacy decreased by $13 \cdot 8 \%$, $19 \cdot 6 \%$ and $55.0 \%$ for $\mathrm{Fe}$, iodine and Se, respectively, and the dietary recommendation for $\mathrm{Zn}$ intake of $5.5 \mathrm{mg} / \mathrm{d}$ was met by all subjects.

Since recommendations for choline intake were published, several studies have reported that choline intakes often do not meet recommendations in both pregnant ${ }^{(51)}$ and non-pregnant individuals ${ }^{(52)}$. Currently no RNI or EAR has been defined for choline; however, in the USA an Adequate Intake (AI) for pregnant women of $450 \mathrm{mg} / \mathrm{d}$ has been established. In our study group choline intake was $198 \mathrm{mg} / \mathrm{d}$. This intake is considerably lower than the AI, despite habitual consumption of eggs that in the current study supplied $33.4 \%$ of the choline intake. However, as with the assessment of dietary iodine intake, dietary choline intakes are likely to have been underestimated owing to the incompleteness of the dietary database.

When interpreting the results of the present survey, the biases associated with conducting dietary surveys must be acknowledged; most notably, under-reporting and the use of standard portion sizes to estimate weights of food consumed. In our study the lack of data on pre-pregnancy weight, combined with the use of an estimated PAL ${ }^{(53)}$, will have influenced the determination of BMR and, subsequently, the calculated cut-off for under-reporting. Therefore, we might have underestimated under-reporting and it is not possible to state conclusively that subjects above the cut-off level determined for under-reporting were actually achieving their energy and/or nutrient requirements. It is also conceivable their levels of under-reporting could have been underestimated owing to reluctance among subjects to report foods accepted as inappropriate during pregnancy, such as alcohol. It is also impossible to state if some foods regarded as being 'healthy' were over-reported. Nevertheless, the levels of under-reporting observed are plausible based on one other study in pregnant women ${ }^{(54)}$ and within the range observed in other studies which used more objective measures to assess energy requirements ${ }^{(55,56)}$. Consequently, we believe the findings are likely to be an accurate reflection of misreporting in this group.

In the absence of biochemical indices of micronutrient status, adequacy of micronutrient intakes was judged against UK dietary recommendations. To reduce the inaccuracies associated with estimating nutritional inadequacy, statistical methods were used to estimate the usual distribution of intakes based on the observed intakes. The variety of foods generally available for consumption in the Seychelles is limited compared with Western societies. This lack of variability may have reduced reporting errors and improved accuracy in assessment of nutrient intake. In addition, piloting and feasibility studies were undertaken in Seychelles prior to initiation of the current dietary survey ${ }^{(27)}$ and adjustments were made to reflect usual dietary intakes. However, while every effort was made to collect accurate records of food intake, the value of the intake data is currently constrained by the lack of comprehensive food composition data.

In conclusion, despite reports of a decline in fish consumption, the Seychellois population had a weekly average (SD) fish intake of 527 (327) g. This intake is almost four times greater than those observed in the $\mathrm{UK}^{(57)}$. Fat intakes were higher than previously reported $^{(26)}$ and in most subjects exceeded the UK DRV for fat as a percentage of energy intake for both total $(<35 \%)$ and saturated $(<10 \%)$ fat. Indeed, macronutrient intakes in pregnant women in Seychelles were similar to intakes reported among pregnant women in the $\mathrm{UK}^{(45)}$. These findings are reflective of a move towards a more Westerntype diet and the emergence of an increased prevalence or risk factors for CHD in the Seychelles ${ }^{(26)}$. Our observation that fish consumption was significantly higher in the subset of subjects who met nutrient recommendations for $\mathrm{Fe}, \mathrm{Zn}$, iodine and Se is an important finding and highlights the critical role of fish in ensuring optimal dietary intakes of key micronutrients during pregnancy. Furthermore, as a source of protein in the Seychellois diet, fish was equivalent to meat but without the associated higher energy and fat content. These findings are of vital public health importance to the Seychellois and emphasise the necessity in maintaining current levels of fish consumption in this population. However, the overall trend towards a lower consumption of fish could become problematic in the future. These findings suggest caution in establishing public health policies that promote limiting fish intake during pregnancy to reduce exposure to methylmercury. Such policies may result in concomitant decreases in important micronutrient intakes and increased energy and fat intakes. Emphasis on the benefits of fish consumption should, therefore, be prioritised.

\section{Acknowledgements}

The research was funded by the National Institute of Environmental Health Sciences (NIEHS) of the US National Institutes of Health (grant number RO1 ES010219). M.P.B. wrote the paper and analysed the dietary data. E.M.D. co-analysed the dietary data. T.W.C., 
G.J.M., P.W.D., C.F.S., J.M.W., P.J.R., J.J.S. and M.B.E.L. were responsible for study design. All authors read and contributed to finalisation of the manuscript. We thank Octavie Choisy, Anne-Marie Bibi and the maternity nurses for all their work with the subjects in the Seychelles. We also acknowledge Seychelles Bureau of Standards and CCFRA Technology Ltd, Chipping Campden, UK for their laboratory analyses of fish samples. There are no conflicts of interest.

\section{References}

1. Mathews F, Yudkin P \& Neil A (1999) Influence of maternal nutrition on outcome of pregnancy: prospective cohort study. BMJ 319, 339-343.

2. Godfrey K, Robinson S, Barker DJP, Osmond C \& Cox V (1996) Maternal nutrition in early and late pregnancy in relation to placental and fetal growth. BMJ 312, 410-414.

3. Gluckman PD \& Hanson MA (2004) Living with the past: evolution, development, and patterns of disease. Science 305, 1733-1736.

4. Roseboom TJ, van der Meulen JH, Osmond C, Barker DJ, Ravelli AC, Schroeder-Tanka JM, van Montfrans GA, Michels RP \& Bleker OP (2000) Coronary heart disease after prenatal exposure to the Dutch famine, 1944-45. Heart 84, 595-598.

5. Hurst DL (1982) Infant malnutrition and mental retardation. $N$ Engl J Med 306, 545-546.

6. Debes F, Budtz-Jorgensen E, Weihe P, White RF \& Grandjean P (2006) Impact of prenatal methylmercury exposure on neurobehavioral function at age 14 years. Neurotoxicol Teratol 28, 363-375.

7. Roos N, Wahab MA, Chamnan C \& Thilsted SH (2007) The role of fish in food-based strategies to combat vitamin A and mineral deficiencies in developing countries. J Nutr 137, 1106-1109.

8. Gibson RS \& Hotz C (2001) Dietary diversification/ modification strategies to enhance micronutrient content and bioavailability of diets in developing countries. $\mathrm{Br} \mathrm{J}$ Nutr 85, S159-S166.

9. Clarkson TW \& Strain JJ (2003) Nutritional factors may modify the toxic action of methyl mercury in fish-eating populations. J Nutr 133, 1539S-1543S.

10. World Health Organization (1998) Global Database on Child Growth and Malnutrition. Geneva: WHO.

11. World Health Organization (1992) The Prevalence of Anemia in Women: A Tabulation of Available Information. Maternal Health and Safe Motherhood Programme. WHO/ $M C H / M S M / 92.2$, 2nd ed. Geneva: WHO.

12. O'Connell KJ, Rakeman MA, Zhi-Hong D, Xue-Yi C, Mei ZY, DeLong N, Brenner G, Tai M, Dong W \& DeLong GR (2002) Effects of iodine supplementation during pregnancy on child growth and development at school age. Dev Med Child Neurol 44, 76-81.

13. Idjradinata P \& Pollitt E (1993) Reversal of developmental delays in iron-deficient anaemic infants treated with iron. Lancet 341, 1-4.

14. Mahomed K, Bhutta Z \& Middleton P (2007) Zinc supplementation for improving pregnancy and infant outcome. The Cochrane Database of Systematic Reviews 2007, issue 18, CD000230. http://mrw.interscience.wiley. com/cochrane/clsysrev/articles/CD000230/pdf_fs.html

15. Kirksey A, Wachs TD, Yunis F, Srinath U, Rahmanifar A, McCabe GP, Galal OM, Harrison GG \& Jerome NW (1994) Relation of maternal zinc nutriture to pregnancy outcome and infant development in an Egyptian village. Am J Clin Nutr 60, 782-792.
16. Merialdi M, Caulfield LE, Zavaleta N, Figueroa A \& DiPietro JA (1999) Adding zinc to prenatal iron and folate tablets improves fetal neurobehavioral development. Am J Obstet Gynecol 180, 483-490.

17. Holben DH \& Smith AM (1999) The diverse role of selenium within selenoproteins: a review. J Am Diet Assoc 99, 836-843.

18. Watanabe C (2001) Selenium deficiency and brain functions: the significance for methylmercury toxicity. Nippon Eiseigaku Zasshi 55, 581-589.

19. Sastry PS (1985) Lipids of nervous tissue: composition and metabolism. Prog Lipid Res 24, 169-176.

20. Clandinin MT, Chappell JE, Leong S, Heim T, Swyer PR \& Chance GW (1980) Intrauterine fatty acid accretion rates in human brain: implications for fatty acid requirements. Early Hum Dev 4, 121-129.

21. Hadders-Algra M, Bouwstra $\mathrm{H}$, van Goor SA, DijckBrouwer DA \& Muskiet FA (2007) Prenatal and early postnatal fatty acid status and neurodevelopmental outcome. J Perinat Med 35, S28-S34.

22. Zeisel SH (2000) Choline: an essential nutrient for humans. Nutrition 16, 669-671.

23. Blusztajn JK, Cermak JM, Holler T \& Jackson DA (1998) Imprinting of hippocampal metabolism of choline by its availability during gestation: implications for cholinergic neurotransmission. J Physiol 91, 199-203.

24. Glenn MJ, Gibson EM, Kirby ED, Mellott TJ, Blusztajn JK \& Williams CL (2007) Prenatal choline availability modulates hippocampal neurogenesis and neurogenic responses to enriching experiences in adult female rats. Eur J Neurosci 25, 2473-2482.

25. Robinson J \& Shroff J (2004) The fishing sector in Seychelles: an overview, with an emphasis on artisanal fisheries. Seychelles Med Dent J 7, 52-58. http:// www.smdj.sc/sectioniid1.HTM

26. Shamlaye CF, Shamlaye H \& Brewer R (2004) Health in Seychelles - an overview. Seychelles Med Dent J 7, 13-20. http://www.smdj.sc/sectioniib1.HTM

27. Robson PJ, Choisy O, Bonham MP, Duffy EM, Wallace JW, Esther CD, Strain JJ \& Livingstone MBE (2004) Development and implementation of a method to assess food and nutrient intakes in the Seychelles Child Development Nutrition Study. Seychelles Med Dent J 7, 100-108. http:// www.smdj.sc/sectionivc.HTM

28. Crawley H (2002) Food Portion Sizes, 3rd ed. London: HM Stationery Office.

29. Sayed N, Frans Y \& Schönfeldt H (1999) Composition of South African Foods: Milk and Milk Products; Eggs; Meat and Meat Products. South Africa: Medical Research Council.

30. Ather N, McLaughlin J \& Taylor G (2003) The Concise New Zealand Food Composition Tables, 6th ed. Palmerston North, New Zealand: New Zealand Institute for Crop and Food Research Limited.

31. United States Department of Agriculture (2004) Database for the choline content of common foods. http://www. nal.usda.gov/fnic/foodcomp/Data/Choline/Choline.html (accessed January 2008).

32. Schofield WN, Schofield C \& James WPT (1985) Basal metabolic rate - review and prediction, together with an annotated bibliography of source material. Hum Nutr Clin Nutr 39, 1-96.

33. Goldberg GR, Black AE, Jebb SA, Cole TJ, Murgatroyd PR, Coward WA \& Prentice AM (1991) Critical evaluation of energy intake data using fundamental principles of energy physiology: 1. Derivation of cut-off limits to identify underrecording. Eur J Clin Nutr 45, 569-581.

34. Black AE (2000) The sensitivity and specificity of the Goldberg cut-off for EI:BMR for identifying diet reports of poor validity. Eur J Clin Nutr 54, 395-404. 
35. Prentice AM, Spaaij CJ, Goldberg GR, Poppitt SD, van Raaij JM, Totton M, Swann D \& Black AE (1996) Energy requirements of pregnant and lactating women. Eur J Clin Nutr 50, S82-S110.

36. Myers GJ, Davidson PW, Cox C et al. (2003) Prenatal methylmercury exposure from ocean fish consumption in the Seychelles Child Development Study. Lancet 361, 1686-1692.

37. National Research Council (1986) Nutrient Adequacy. Assessment Using Food Composition Surveys. Washington, DC: National Academy Press.

38. Morimoto JM, Marchioni DM \& Fisberg RM (2006) Using dietary reference intake-based methods to estimate prevalence of inadequate nutrient intake among female students in Brazil. J Am Diet Assoc 106, 733-736.

39. Department of Health (2001) Dietary Reference Values for Food Energy and Nutrients for the United Kingdom. Report of the Panel on Dietary Reference Values of the Committee on Medical Aspects of Food Policy. London: HMSO.

40. Institute of Medicine (2000) Dietary Reference Values: Applications in Dietary Assessment. Washington, DC: National Academy Press.

41. Davidson PW, Myers GJ, Cox C, Wilding GE, Shamlaye CF, Huang LS, Cernichiari E, Sloane-Reeves J, Palumbo D \& Clarkson TW (2006) Methylmercury and neurodevelopment: longitudinal analysis of the Seychelles child development cohort. Neurotoxicol Teratol 28, 529-535.

42. Bonham MP, Duffy EM, Wallace JMW, Robson PJ, Myers GJ, Davidson PW, Clarkson TW, Shamlaye CF \& Strain JJ (2008) Habitual fish consumption does not prevent a decrease in LCPUFA status in pregnant women (the Seychelles Child Development Nutrition Study). Prostaglandins Leukot Essent Fatty Acids 78, 343-350.

43. Institute of Medicine (1990) Iron Nutrition during Pregnancy. Washington, DC: National Academy of Sciences.

44. Wallace JMW, Bonham MP, Strain JJ et al. (2008) Homocysteine concentration, related $\mathrm{B}$-vitamins. and betaine in pregnant women recruited to the Seychelles Child Development Study. Am J Clin Nutr 87, 391-397.

45. Mouratidou T, Ford F, Prountzou F \& Fraser R (2006) Dietary assessment of a population of pregnant women in Sheffield, UK. BrJ Nutr 96, 929-935.

46. de Lourdes Flores M, Neufeld LM, González-Cossío T, Rivera J, Martorell R \& Ramakrishnan U (2007) Multiple micronutrient supplementation and dietary energy intake in pregnant women. Salud Publica Mex 49, 190-198.

47. Kesa H \& Oldewage-Theron W (2005) Anthropometric indications and nutritional intake of women in the Vaal Triangle, South Africa. Public Health 119, 294-300.

48. Zimmermann M \& Delange F (2004) Iodine supplementation of pregnant women in Europe: a review and recommendations. Eur J Clin Nutr 58, 979-984.

49. Smallridge RC \& Ladenson PW (2001) Hypothyroidism in pregnancy: consequences to neonatal health. J Clin Endocrinol Metab 86, 2349-2353.

50. Maret W \& Sandstead HH (2006) Zinc requirements and the risks and benefits of zinc supplementation. J Trace Elem Med Biol 20, 3-18.

51. Gossell-Williams $\mathrm{M}$, Fletcher $\mathrm{H}$, McFarlane-Anderson $\mathrm{N}$, Jacob A, Patel J \& Zeisel S (2005) Dietary intake of choline and plasma choline concentrations in pregnant women in Jamaica. West Indian Med J 54, 355-359.

52. Chiuve SE, Giovannucci EL, Hankinson SE, Zeisel SH, Dougherty LW, Willett WC \& Rimm EB (2007) The association between betaine and choline intakes and the plasma concentrations of homocysteine in women. Am J Clin Nutr 86, 1073-1081.

53. Black AE (2002) Critical evaluation of energy intake using the Goldberg cut-off for energy intake:basal metabolic rate. A practical guide to its calculation, use and limitations. Int J Obes Relat Metab Disord 24, 1119-1130.

54. Okubo H \& Sasaki S (2004) Underreporting of energy intake among Japanese women aged 18-20 years and its association with reported nutrient and food group intakes. Public Health Nutr 7, 911-917.

55. Schoeller DA (1995) Limitations in the assessment of dietary energy intake by self-report. Metabolism $\mathbf{4 4}$, $18-22$.

56. Subar AF, Kipnis V, Troiano RP et al. (2003) Using intake biomarkers to evaluate the extent of dietary misreporting in a large sample of adults: the OPEN study. Am J Epidemiol 158, $1-13$.

57. UK Scientific Advisory Committee on Nutrition (2006) Advice on fish consumption: benefits and risk. Joint report of the Scientific Advisory Committee on Nutrition (SACN) and Committee on Toxicity, UK Food Standards Agency. www.sacn.gov.uk/pdfs/fics_sacn_advice_fish.pdf (accessed January 2008). 